\title{
Probing the Mechanism of Sodium Ion Insertion into Copper Antimony $\mathrm{Cu}_{2} \mathrm{Sb}$ Anodes
}

Loïc Baggetto, ${ }^{* \dagger}$ Kyler J. Carroll, ${ }^{\ddagger}$ Hien-Yoong Hah, ${ }^{\S} \|$ Charles E. Johnson, ${ }^{\S}$ David R. Mullins, ${ }^{\perp}$ Raymond R. Unocic, ${ }^{\dagger}$ Jacqueline A. Johnson, ${ }^{\S, \uparrow l}$ Ying Shirley Meng, ${ }^{\ddagger}$ and Gabriel M. Veith*,

${ }^{\dagger}$ Materials Science and Technology Division, Oak Ridge National Laboratory, Oak Ridge, Tennessee 37831, United States

${ }^{\ddagger}$ Department of NanoEngineering, University of California, San Diego, La Jolla, California 92037, United States

${ }^{\S}$ Center for Laser Applications, University of Tennessee Space Institute, Tullahoma, Tennessee 37388, United States

"Department of Mechanical, Aeronautical and Biomedical Engineering, University of Tennessee Space Institute, Tullahoma, Tennessee 37388, United States

${ }^{\perp}$ Chemical Sciences Division, Oak Ridge National Laboratory, Oak Ridge, Tennessee 37831, United States

\section{Supporting Information}

ABSTRACT: We report experimental studies to understand the reaction mechanism of the intermetallic anode $\mathrm{Cu}_{2} \mathrm{Sb}$ with $\mathrm{Na}$ and demonstrate that it is capable of retaining about 250 $\mathrm{mAh} \mathrm{g}^{-1}$ over 200 cycles when using fluoroethylene carbonate additive. X-ray diffraction data indicate during the first discharge the reaction leads to the formation of crystalline $\mathrm{Na}_{3} \mathrm{Sb}$ via an intermediate amorphous phase. Upon desodiation the $\mathrm{Na}_{3} \mathrm{Sb}$ reverts to an amorphous phase, which then recrystallizes into $\mathrm{Cu}_{2} \mathrm{Sb}$ at full charge, indicating a high degree of structural reversibility. The structure after charging to $1 \mathrm{~V}$ is different from that of $\mathrm{Cu}_{2} \mathrm{Sb}$, as indicated by X-ray absorption spectroscopy and ${ }^{121} \mathrm{Sb}$ Mössbauer spectroscopy, and is due to the formation of an amorphous $\mathrm{Na}-\mathrm{Cu}-\mathrm{Sb}$ phase. At full discharge, an isomer shift of $-8.10 \mathrm{~mm} \mathrm{~s}^{-1}$ is measured, which is close to that of a Na $\mathrm{Na}_{3} \mathrm{Sb}$ reference powder $\left(-7.95 \mathrm{~mm} \mathrm{~s}^{-1}\right)$ and in agreement with the formation of $\mathrm{Na}_{3} \mathrm{Sb}$ domains. During charge, the isomer shift at $1 \mathrm{~V}\left(-9.29 \mathrm{~mm} \mathrm{~s}^{-1}\right)$ is closer to that of the pristine material $\left(-9.67 \mathrm{~mm} \mathrm{~s}^{-1}\right)$, but the lower value is consistent with the lack of full desodiation, as expected from the potential profile and the XAS data.

\section{INTRODUCTION}

Recently, there has been a surge of activity to identify stable materials for sodium-ion batteries. ${ }^{1-4}$ This surge is fueled by the desire to find alternative energy storage technologies to the ubiquitous lithium-ion chemistries with an emphasis on sustainable systems using low cost and naturally abundant chemical elements. Compared to $\mathrm{Na}$-ion cathodes, the investigation of Na-ion anode materials is in its infancy. ${ }^{1-4}$ Recently, there have been several significant advances in the study of sodium-ion anode materials. ${ }^{5-19}$ The discovery of new applicable chemistry in intercalation compounds, such as $\mathrm{Na}_{2} \mathrm{Ti}_{3} \mathrm{O}_{7}, 5$ or hard carbons ${ }^{6,7}$ are obvious examples. These chemistries, however, suffer from relatively low storage capacity, especially on a volumetric basis.

In order to increase the anode storage capacity and rate performance, metallic systems have been studied. The most promising elements to deliver high storage capacity are $\mathrm{Sn}^{8,9}$ and $\mathrm{Sb},{ }^{10,11}$ which have large theoretical storage capacities up to 847 and $660 \mathrm{mAh} \mathrm{g}^{-1}$, respectively. A natural progression of this research is the investigation of intermetallic anodes which have a number of advantages over their pure counterparts such as enhanced capacity retention and faster kinetics as demonstrated for Li-ion batteries. ${ }^{12}$ This triggered the exploration of several $\mathrm{Sb}$ - and $\mathrm{Sn}$-based intermetallic compounds, such as $\mathrm{SnSb},{ }^{13} \mathrm{Cu}_{6} \mathrm{Sn}_{5},{ }^{14} \mathrm{Cu}_{2} \mathrm{Sb},{ }^{15,16} \mathrm{AlSb},{ }^{17}$ and $\mathrm{Mo}_{3} \mathrm{Sb}_{7}{ }^{18}$ as well as neighboring elements like $\mathrm{Ge}^{19}$ and In. ${ }^{20}$

One potential intermetallic anode of great interest is $\mathrm{Cu}_{2} \mathrm{Sb}$, which demonstrates high $\mathrm{Na}$ storage capacity (250-290 mAh $\mathrm{g}^{-1}$ or $2100-2400 \mathrm{mAh} \mathrm{cm} \mathrm{cm}^{-3}$ ) and very high rate performance $(10 \mathrm{C}) .{ }^{15}$ In a previous study of the reaction end products using $\mathrm{X}$-ray diffraction (XRD), we identified nanocrystalline $\mathrm{Na}_{3} \mathrm{Sb}$ $(P 63 / m m c)$ as the end-member of the Na-ion electrochemical reaction, ${ }^{15}$ which was recently confirmed. ${ }^{16}$ The present contribution dwells much further into the $\mathrm{Na}$-ion reaction mechanism of $\mathrm{Cu}_{2} \mathrm{Sb}$ by extending the XRD investigation using Mo $\mathrm{K} \alpha$ radiation at several electrode potentials during the first and second cycles. In addition, we report the local atomic structure of the electrode material with the aid of synchrotronbased X-ray absorption near-edge spectroscopy (XANES) and extended X-ray absorption fine structure (EXAFS) techniques at both the $\mathrm{Cu}$ K-edge and $\mathrm{Sb} \mathrm{K}$-edge, and the local chemical

Received: January 29, 2014

Revised: $\quad$ March 21, 2014

Published: March 25, 2014 
(a)

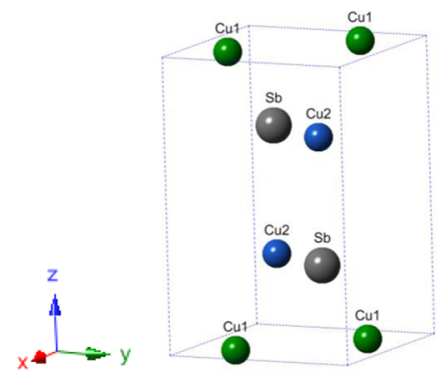

(b)

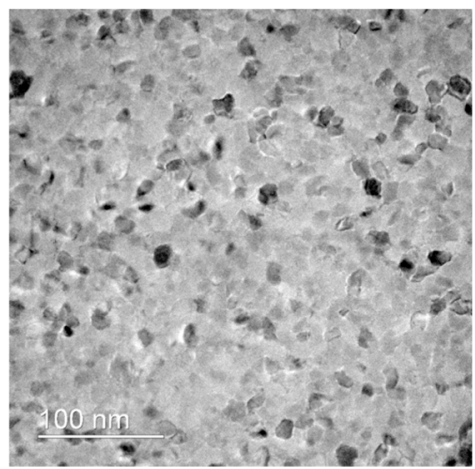

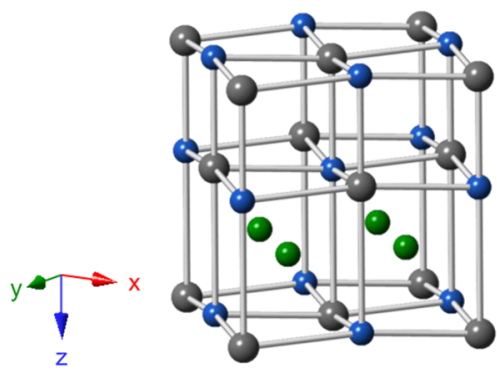

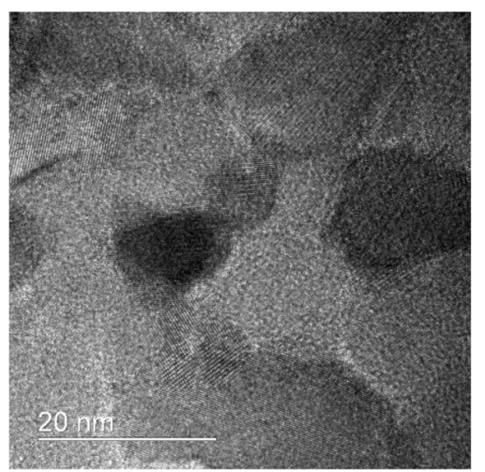

Figure 1. (a) Schematic representation of $P 4 / n m m$ tetragonal $\mathrm{Cu}_{2} \mathrm{Sb}$ crystal structure. The left-hand-side figure shows a tetragonal subcell of the full unit cell (Figure S1). The right-hand-side figure represents the distorted fcc $\mathrm{Sb}$ cell which encompasses four $\mathrm{Cu}_{2} \mathrm{Sb}$ formula units. (b) TEM characterization of the pristine thin films. The left-hand-side figure shows a BFTEM photograph of the film deposited onto an electron transparent $\mathrm{SiN}_{x}$ window, and the right-hand-side figure displays a high-resolution TEM photograph of the same film.

environment of $\mathrm{Sb}$ using ${ }^{121} \mathrm{Sb}$ Mössbauer spectroscopy, with the aid of $\mathrm{Cu}_{2} \mathrm{Sb}, \mathrm{Sb}$, and $\mathrm{Na}_{3} \mathrm{Sb}$ reference compounds.

\section{EXPERIMENTAL SECTION}

2.1. Sample Preparation. Thin films were deposited onto roughened $\mathrm{Cu}$ foil, or an $\mathrm{Al}$ foil, using $\mathrm{dc}$ magnetron sputtering in $\mathrm{Ar}$, as reported earlier. ${ }^{15}$ In brief, sputter deposition conditions for $\mathrm{Cu}_{2} \mathrm{Sb}$ are $30 \mathrm{~W}$ (power), $15 \mathrm{mT}$ Torr (pressure), and $5 \mathrm{~cm}$ target-substrate distance. With $\mathrm{Al}$ substrates a $\mathrm{Cr}$ adhesion layer was deposited at $30 \mathrm{~W}, 20 \mathrm{mTorr}$, and with a 5 $\mathrm{cm}$ target-substrate distance. After preparation, all the samples were stored inside an Ar-filled glovebox. For XRD and Mössbauer spectroscopy measurements, relatively thick films $(\sim 2-4 \mu \mathrm{m})$ were deposited onto roughened $\mathrm{Cu}$ foil to obtain sufficient signal. For materials used in Mössbauer spectroscopy measurements, the charge was limited to $1 \mathrm{~V}$ due to delamination of the comparatively thick films $(\sim 3-4 \mu \mathrm{m})$. For $\mathrm{Cu}$ K-edge XAS, the use of $\mathrm{Al}$ is essential to prevent absorption by the $\mathrm{Cu}$ collector foil. However, using Al limits the study of the charge to $1 \mathrm{~V}$ due to the poor adhesion of $\mathrm{Cu}_{2} \mathrm{Sb}$ onto this material.

A reference powder of $\mathrm{Na}_{3} \mathrm{Sb}$ was prepared inside an Ar-filled glovebox by adding stoichiometric amounts of $\mathrm{Na}$ (SigmaAldrich) and ball-milled Sb (99+\%, Alfa Aesar) inside a homemade $\mathrm{Al}$ foil crucible placed inside a Pyrex tube. Using a Swagelok fitting connected to a vacuum valve, a primary vacuum was created inside the tube. Subsequently, the tube was placed in an oven at $175{ }^{\circ} \mathrm{C}$ for several hours. As soon as the $\mathrm{Na}$ melted, it reacted with $\mathrm{Sb}$ to form a solid compound. The recovered powder was ground thoroughly, pressed into a pellet, and further annealed at $175{ }^{\circ} \mathrm{C}$. This procedure was repeated to ensure homogeneity of the compound. The recovered powder was conditioned under Ar for further XRD, XAS, and Mössbauer spectroscopy analyses.
2.2. Characterization. Electrochemical characterization was conducted at $25{ }^{\circ} \mathrm{C}$ with two-electrode 2032 coin cells prepared inside an Ar-filled glovebox using pure $\mathrm{Na}$ as the counter electrode and two disks of glass fiber separators impregnated with $1 \mathrm{M} \mathrm{NaClO}_{4}$ (Sigma-Aldrich) dissolved in anhydrous propylene carbonate (PC, Sigma-Aldrich) electrolyte. When specified, 5 wt \% anhydrous fluoroethylene carbonate (FEC, Sigma-Aldrich) was used as an electrolyte additive. Cycling with a constant current (CC) and with a constant current combined with a constant voltage hold (CCCV) were performed with a Maccor 4000 battery cycler. For XRD, XAS, and Mössbauer spectroscopy characterization, specimens were extracted from coin cells inside an Ar-filled glovebox, pressed onto a fiber paper to remove the excess electrolyte, sealed with Kapton tape, and packaged under Ar inside heat-sealed pouch bags. The electrodes were not washed prior to analysis since the studies focused on the bulk structures not the surface chemistries.

A Bruker D8 Advance diffractometer with Mo K $\alpha$ source and Zr filter was used for XRD collection. Cycled electrodes were sealed onto a glass slide using Kapton tape. ${ }^{8,10,14-19}$ For $\mathrm{Na}_{3} \mathrm{Sb}$ powder data acquisition, the ground powder was loaded inside a $0.5 \mathrm{~mm}$ glass capillary which was heat-sealed with a methaneoxygen torch.

Transmission electron microscopy (TEM) was performed using a Hitachi HF3300 S/TEM instrument operating at 300 $\mathrm{kV}$. A $30 \mathrm{~nm}$ thick film deposited onto an electron transparent $\mathrm{SiN}_{x}$ membrane of a TEM chip was used for characterizing the structure of the pristine material.

XAS data were recorded at the Cu K-edge $(8979 \mathrm{eV})$ and $\mathrm{Sb}$ K-edge $(30491 \mathrm{eV})$ at beamlines X19a and X18b, respectively, of the National Synchrotron Light Source, at Brookhaven National Laboratory. A Si(111) double crystal monochromator was used, and in the case of $\mathrm{Cu}$ K-edge measurements, the 
monochromator was detuned $30 \%$ to reject higher harmonics. XAS was measured simultaneously in transmission and fluorescence. For the $\mathrm{Cu}$ K-edge, ion chambers for measuring $I_{0}$ and $I_{t}$ were filled with a 50:50 mixture of $\mathrm{N}_{2}$ :Ar. For the $\mathrm{Sb}$ K-edge, ion chambers for measuring $I_{0}$ and $I_{t}$ were filled with $100 \% \mathrm{Ar}$ and a 50:50 mixture of $\mathrm{Kr}: \mathrm{N}_{2}$, respectively. Fluorescence was measured using a large area passivated implanted planar silicon (PIPS) detector perpendicular to the incident beam. All data were recorded at room temperature on samples sealed in $\mathrm{Al}$ pouch bags. $\mathrm{Sb}, \mathrm{Cu}_{2} \mathrm{Sb}$, and $\mathrm{Na}_{3} \mathrm{Sb}$ powders, $\mathrm{Cu}_{2} \mathrm{Sb}$ pristine films, and $\mathrm{Cu}$ foil were measured as references. The programs ATHENA (version 0.8.061) and ARTEMIS (version 0.8.014) were used to reduce and fit the EXAFS data, respectively. ${ }^{20}$ Data reduction consisted of preedge subtraction, background determination, normalization, and spectral averaging. The $k^{3}$ - and $k^{1}$-weighted EXAFS functions, $\chi(k)$, were Fourier transformed and fitted in $R$ space.

${ }^{121} \mathrm{Sb}$ Mössbauer spectroscopy was recorded in the constant acceleration mode using a system manufactured by SEE Co., Edina, MN. The source was $100 \mu \mathrm{Ci}$ of ${ }^{121 \mathrm{~m}} \mathrm{Sn}$ in $\mathrm{BaSnO}_{3}$ at room temperature, and a $\mathrm{Xe}-\mathrm{CH}_{4}$ proportional counter was used to detect the sum of the $37.2 \mathrm{keV} \gamma$-rays and $8 \mathrm{keV}$ escape peak. Several thick electrodes, providing around $20 \mathrm{mg}$ of starting $\mathrm{Cu}_{2} \mathrm{Sb}$ material, were measured simultaneously to provide enough absorption. The samples were cooled to $6-7 \mathrm{~K}$ under vacuum in a closed-cycle cryogen-free refrigerator (Janis, Wilmington, MA, and SEE Co.), partly to increase the Mössbauer fraction and partly to suppress the materials oxidation. The velocity scale was calibrated with an ${ }^{57} \mathrm{Fe}$ absorber and a $\mathrm{Rh}^{57} \mathrm{Co}$ source and is quoted relative to the $\mathrm{BaSnO}_{3}$ source. The spectra were fitted with a custom Mössbauer program using a Lorentzian line profile. Powders of $\mathrm{Sb}, \mathrm{Cu}_{2} \mathrm{Sb}$, and $\mathrm{Na}_{3} \mathrm{Sb}$ were used as references.

\section{RESULTS AND DISCUSSION}

3.1. Electrochemical Properties of $\mathrm{Cu}_{2} \mathrm{Sb}$ Anode versus $\mathrm{Na}$. The structure of $\mathrm{Cu}_{2} \mathrm{Sb}(\mathrm{P} 4 / \mathrm{nmm})$ is a tetragonal unit cell (Figure $\mathrm{S} 1$ ), of which a subcell comprising a single $\mathrm{Cu}_{2} \mathrm{Sb}$ formula unit is depicted in Figure 1a. The tetragonal structure can also be described as a distorted face-centered cubic (fcc) Sb structure with dimensions of $\sim 5.6 \times 5.6 \times 6.1 \AA$ (Figure 1a). Within this pseudo-fcc structure, half of the $\mathrm{Cu}$ atoms ( $\mathrm{Cu} 1$, green atoms) occupy half of the tetrahedral sites whereas the other half ( $\mathrm{Cu} 2$, blue atoms) are located in the distorted octahedra. The structure of the starting films has been characterized by TEM. The material deposited onto a $\mathrm{SiN}_{x}$ window is composed of small grains with diameters from 5 to $20 \mathrm{~nm}$. The presence of a crystalline material is clearly evidenced by the presence of lattice fringes and variations in contrast due to differences in crystal orientation (Figure $1 \mathrm{~b}$ ).

The electrochemical properties of $\mathrm{Cu}_{2} \mathrm{Sb}$ as an anode material for $\mathrm{Na}$-ion batteries are presented in Figure 2. The cycling performance of the films cycled in $\mathrm{NaClO}_{4}$ dissolved in $\mathrm{PC}$ was formerly found to be satisfactory for tens of cycles only (blue curve, Figure 2a). ${ }^{15}$ The use of appropriate electrolyte additives, such as FEC, promotes the cycle life of metallic anodes significantly ${ }^{11,13,16-20}$ thanks to the formation of a more stable inorganic solid electrolyte interphase (SEI) layer. ${ }^{10,18}$ Two electrodes cycled with FEC additive show significantly improved capacity retention (Figure $2 \mathrm{a}$, green and red curves). For these thicker electrodes, the slow increase of capacity during the first few cycles is related to the use of FEC, which induces the presence of larger overpotentials $(0.15-0.2 \mathrm{~V})$
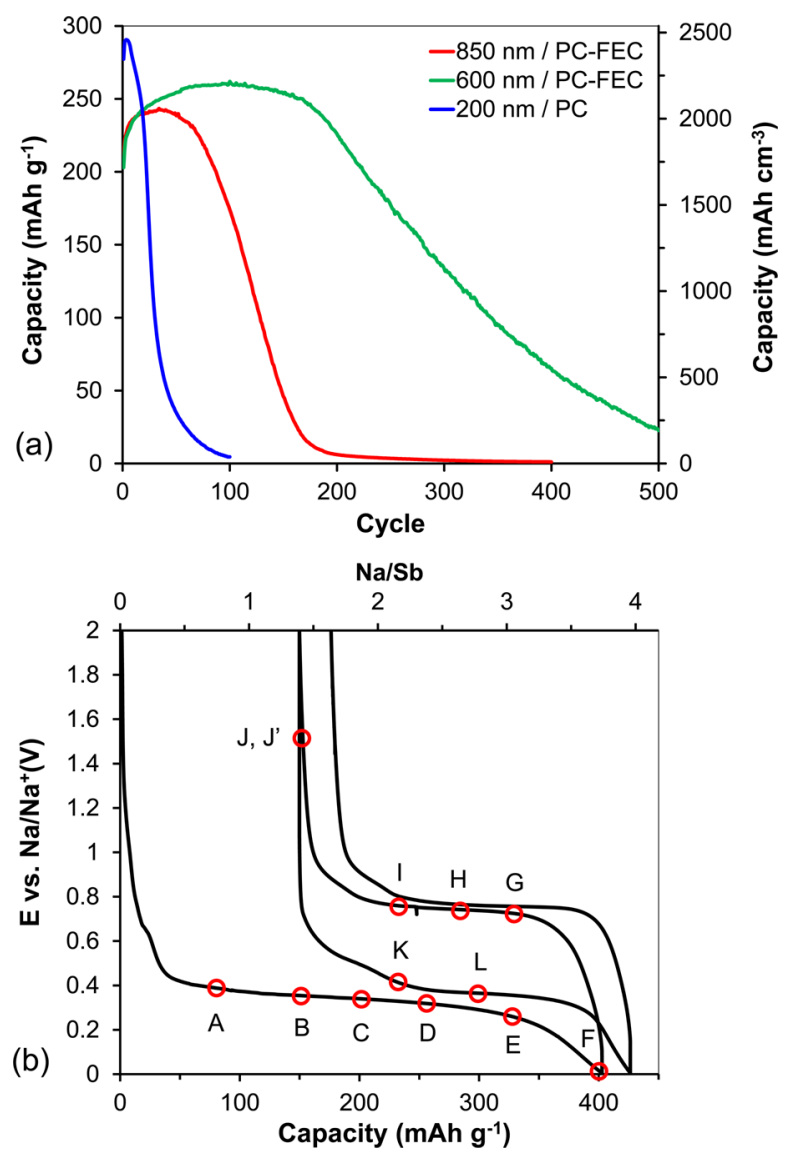

Figure 2. Electrochemical characterizations of $\mathrm{Cu}_{2} \mathrm{Sb}$ thin films during the Na-ion reaction. (a) Cycle life of $\mathrm{Cu}_{2} \mathrm{Sb}$ electrodes cycled at $80 \mu \mathrm{A}$ $\mathrm{cm}^{-2}$ from 0 to $1 \mathrm{~V}$ in a PC/FEC electrolyte compared the electrode cycled in pure PC. ${ }^{15}$ (b) Typical electrochemical potential profiles during the first two cycles for an electrode measured at $20 \mu \mathrm{A} \mathrm{cm}^{-2}$ in PC-based electrolyte. The letters and closed markers indicate the electrodes selected for XRD characterization (Figure 3).

during discharge that eventually decrease upon further cycling (Figure S2). The presence of larger overpotentials was previously observed in the case of $\mathrm{Ge}^{19}$ and was measured systematically for $\mathrm{Mo}_{3} \mathrm{Sb}_{7}, \mathrm{AlSb}$, and $\mathrm{SnSb}$ thin film electrodes of similar thicknesses (not presented). The stable capacities around $250 \mathrm{mAh} \mathrm{g}^{-1}$, measured for these thicker films (600$850 \mathrm{~nm}$ ), are somewhat lower compared to the thin electrode $\left(290 \mathrm{mAh} \mathrm{g}^{-1}\right)$. This difference is due to the better diffusion kinetics of thinner films, which allows access to almost all the electrode material volume under the present experimental conditions $\left(80 \mu \mathrm{A} \mathrm{cm}{ }^{-2}\right)$. Nonetheless, it is clear that the application of $5 \mathrm{wt} \%$ FEC to the electrolyte greatly improves the capacity retention of thicker electrodes over hundreds of cycles with a stable capacity of about $250 \mathrm{mAh} \mathrm{g}^{-1}$ (Figure 2a). This important improvement is likely related to the formation of a much more stable inorganic SEI layer rich in $\mathrm{NaF}$, as we discussed earlier, ${ }^{10,18}$ and demonstrates the potential of $\mathrm{Cu}_{2} \mathrm{Sb}$ anode materials for $\mathrm{Na}$-ion batteries. When a thicker film is used $(850 \mathrm{~nm})$, the capacity declines faster than for a thinner film $(600 \mathrm{~nm})$ due to the larger volume changes of the thicker layer.

The electrochemical reaction of $\mathrm{Cu}_{2} \mathrm{Sb}$ electrodes during the first two cycles is now discussed. During the initial sodiation, the potential profile is dominated by a pronounced plateau centered around $0.35 \mathrm{~V}$. The associated capacity is significantly 
larger than during the following discharges, which also show a slope around $0.5 \mathrm{~V}$. The longer discharge plateau is mostly related to Coulombic losses due to electrolyte decomposition since the reaction during the initial discharge consists not only of the electrode bulk reaction but also shows the passivation of the electrode, current collector, and coin cell hardware surfaces in contact with the electrolyte. The discharge (sodiation) capacity amounts to about $400 \mathrm{mAh} \mathrm{g}^{-1}$ or $3.7 \mathrm{Na} / \mathrm{Sb}$, which corresponds to the bulk reaction (Na-ion insertion into $\mathrm{Cu}_{2} \mathrm{Sb}$ as much as $3 \mathrm{Na} / \mathrm{Sb}$ expected) and the surface reactions discussed above. The charge voltage profiles are virtually identical with a large plateau around $0.75 \mathrm{~V}$ and a small slope near $0.9 \mathrm{~V}$. The charge (desodiation) capacity measured on a thick electrode $(3 \mu \mathrm{m})$ is equal to about $250 \mathrm{mAh} \mathrm{g}^{-1}$ or 2.3 $\mathrm{Na} / \mathrm{Sb}$. This indicates that either full sodiation did not occur during discharge or that some $\mathrm{Na}$ is trapped inside in the material. Since the structural characterization data (XRD, XAS, Mössbauer spectroscopy, see next) support the occurrence of full sodiation, we suppose that the lower reversible storage capacity results from the absence of full desodiation due to diffusion limitations, in particular for thicker films. XPS data collected on $\mathrm{Cu}_{2} \mathrm{Sb}^{15}$ samples show lower than expected binding energies of the $\mathrm{Sb}$ core levels upon desodiation consistent with the hypothesis of trapped $\mathrm{Na}$.

3.2. Characterization of the Electrode Material Structure by XRD. The mechanism during the reaction with $\mathrm{Li}$ is first discussed to serve as a reference for the reaction with $\mathrm{Na}$. During the reaction with $\mathrm{Li}$, all $\mathrm{Cu} 2$ atoms from the distorted octahedral sites are substituted by $\mathrm{Li}$ atoms, which leads to a slight displacement of the $\mathrm{Sb}$ atoms to form an ideal fcc cell in the form of $\mathrm{Li}_{2-2 x} \mathrm{Cu}_{1+x} \mathrm{Sb}(0<x<1){ }^{22,23}$ Further insertion of $\mathrm{Li}$ ions takes place in the tetrahedral sites with cooperative displacement of the $\mathrm{Cul}$ atoms to the neighboring tetrahedral site. Overall, these two steps lead to the extrusion of one $\mathrm{Cu}$ atom and the insertion of two $\mathrm{Li}$ atoms per formula unit of $\mathrm{Cu}_{2} \mathrm{Sb}$. The reaction thereby results in the formation of cubic $\mathrm{Li}_{2} \mathrm{CuSb}(F \overline{4} 3 m)$ with significantly elongated $\mathrm{Sb}-\mathrm{Sb}$ bonds and a lattice parameter of $6.27 \AA^{22,23} \mathrm{Li}_{2} \mathrm{CuSb}$ structure is an $\mathrm{Sb}$ fcc array with one $\mathrm{Li}$ and all $\mathrm{Cu}$ alternately occupying the eight tetrahedral sites and the second $\mathrm{Li}$ occupying the four octahedral sites. Further reaction takes place by substituting the $\mathrm{Cu}$ atoms remaining in the tetrahedral sites to form cubic $\mathrm{Li}_{3} \mathrm{Sb}$ $(F m \overline{3} m)$ with a lattice parameter of $6.56 \AA$. This structure is normally only obtained at high pressures but known to form electrochemically at room temperature and adopts an Sb fcc array with full occupation of the tetrahedral and octahedral sites by $\mathrm{Li}^{22-24}$

The investigation of the electrode structure at various degrees of sodiation during the first and second cycles, as marked by the red closed circles labeled A to $L$ in Figure $2 b$, has been studied by $\mathrm{XRD}$ using Mo $\mathrm{K} \alpha$ radiation. The corresponding XRD patterns are presented in Figure 3, which also includes the pattern for a pristine film. For the cycled electrodes, the broad hump at low angle originates from the Kapton material. The pristine film material is composed of nanocrystallites with broad peaks centered on the positions expected for $\mathrm{P} 4 / \mathrm{nmm} \mathrm{Cu}_{2} \mathrm{Sb}$ (blue bars). The results show some preferred crystallite orientation within the thin film, as evidenced by (111) and (112) peaks at $15.9^{\circ}$ and $19.7^{\circ}$ that are stronger than for the reference pattern (blue bars). This analysis does not take into account that the film was measured with a fixed divergence slit, which for thin films does not respect the constant volume approximation. In fact, the amount

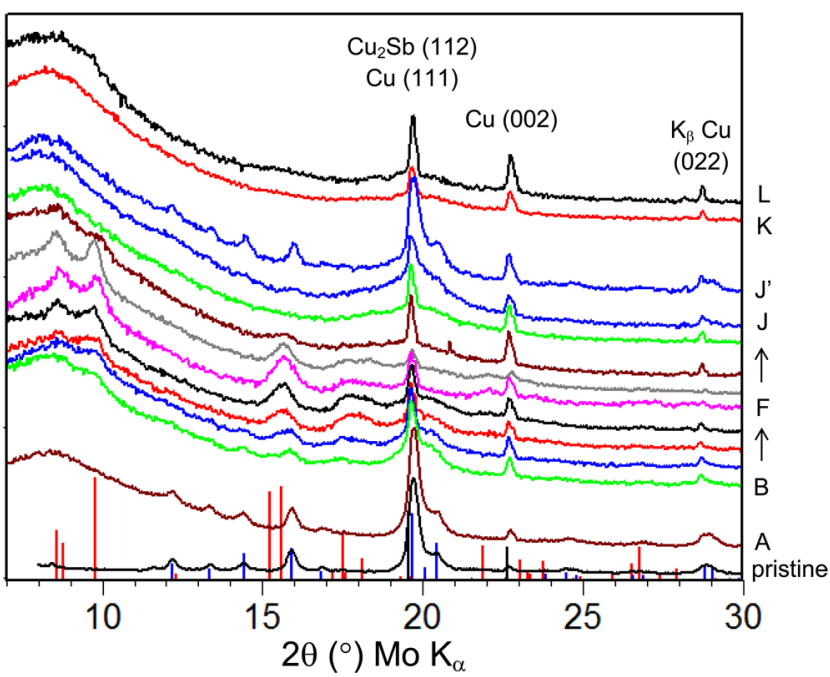

Figure 3. $\mathrm{XRD}$ patterns of $\mathrm{Cu}_{2} \mathrm{Sb}$ electrodes marked in Figure 2b. Red, blue, and black bars indicate $\mathrm{Na}_{3} \mathrm{Sb}, \mathrm{Cu}_{2} \mathrm{Sb}$, and $\mathrm{Cu}$ expected diffraction lines. The overlap of $\mathrm{Cu}_{2} \mathrm{Sb}$ (112) strongest line with the $\mathrm{Cu}(002)$ weak line is highlighted. Note that the $\mathrm{Cu}$ foil is strongly (022) preferentially oriented, which results in the presence of a $\mathrm{K}_{\beta}$ line. For further clarity, see the magnification presented in Figure S3.

of material present in the beam at low diffraction angles can be significantly larger than at larger angles, thereby minimizing the intensity of the (111) and (121) compared to the lower angle peaks.

During discharge (Na-ion insertion), the reaction starts by the conversion of $\mathrm{Cu}_{2} \mathrm{Sb}$ into a material with no characteristic diffraction lines (position $\mathrm{A}$ ), such as possibly an amorphous phase (Figure 3). The reaction further progresses by the formation of nanocrystalline $\mathrm{Na}_{3} \mathrm{Sb}$ (see lines at $8.5-10^{\circ}, 15-$ $16^{\circ}$, and $17.5^{\circ}$, positions $\mathrm{B}-\mathrm{D}$; see Figure S3 for clarity) and the absence of diffraction lines from other phases except $\mathrm{Cu}_{2} \mathrm{Sb}$. It is clear that the diffraction peaks of $\mathrm{Cu}_{2} \mathrm{Sb}$, especially those from $12^{\circ}$ to $16^{\circ}$, the strong (112) peak at $19.7^{\circ}$, and the (020) peak at $20.4^{\circ}$ all decrease in intensity. At point $\mathrm{D}$, the diffraction lines from $\mathrm{Cu}_{2} \mathrm{Sb}$ have almost vanished. These results suggest that $\mathrm{Cu}_{2} \mathrm{Sb}$ has converted completely into an amorphous phase and $\mathrm{Na}_{3} \mathrm{Sb}$ around position D. Moreover, the gradual consumption of $\mathrm{Cu}_{2} \mathrm{Sb}$ and the concomitant formation of $\mathrm{Na}_{3} \mathrm{Sb}$ suggest a reaction front from the surface to the bulk of the film. By comparison with the electrochemical reaction of pure $\mathrm{Sb}$ with $\mathrm{Na}$, the formation of crystalline $\mathrm{NaSb}$ intermediate is not expected, and instead an amorphous phase formed ${ }^{11}$ as also measured here. Further sodiation from $\mathrm{E}$ to $\mathrm{F}$ leads to the growth of the peaks associated with $\mathrm{Na}_{3} \mathrm{Sb}$, whereas the peaks related to $\mathrm{Cu}_{2} \mathrm{Sb}$ are not present anymore (Figure S2). The growth of the peaks related to $\mathrm{Na}_{3} \mathrm{Sb}$ can therefore be attributed to the sodiation of the amorphous phase.

During charge (Na-ion removal, positions $\mathrm{G}$ to $\mathrm{J} / \mathrm{J}^{\prime}$ ), XRD data indicate the $\mathrm{Na}_{3} \mathrm{Sb}$ converts into an amorphous phase as no lines due to crystalline phases are observed until point $\mathrm{J}$. At position $\mathrm{J}(\mathrm{CCCV}$ to $1.5 \mathrm{~V}$ with cutoff of $\mathrm{C} / 30$ ) the presence of very broad humps related to $\mathrm{Cu}_{2} \mathrm{Sb}$ are observed from $13^{\circ}$ to $16^{\circ}$ and around $20.5^{\circ}$. At position $\mathrm{J}^{\prime}$, which is an electrode prepared with a more thorough desodiation by employing a current cutoff of $\mathrm{C} / 50$, diffraction lines of nanocrystalline $\mathrm{Cu}_{2} \mathrm{Sb}$ are now clearly visible. The presence of these lines demonstrates that the reaction can proceed reversibly if a deep 
extraction of $\mathrm{Na}$ is conducted at $1.5 \mathrm{~V}$ and strengthens the view that full structural reversibility requires higher electrode potentials and/or longer hold times. During the second discharge, the addition of $\mathrm{Na}$ on the new slope centered around $0.5 \mathrm{~V}$ (positions $\mathrm{K}$ and $\mathrm{L}$ ) results in the presence of an amorphous phase. Since the second charge is very similar to the first charge (Figure $2 b$ ), we suspect that further addition of $\mathrm{Na}$ from point $\mathrm{L}$ to $0 \mathrm{~V}$ results in the formation of crystalline $\mathrm{Na}_{3} \mathrm{Sb}$.

During the reaction of $\mathrm{Cu}_{2} \mathrm{Sb}$ with $\mathrm{Na}$, the formation of a solid solution or of a new intermediate crystalline phase is not evidenced. This is suggested by the reaction of $\mathrm{Sb}$, which proceeds by the formation of an amorphous phase until hexagonal $P 63 / m m c \quad \mathrm{Na}_{3} \mathrm{Sb}$ crystallizes. ${ }^{11}$ Although the formation of the high-pressure cubic $F m \overline{3} m \mathrm{Na}_{3} \mathrm{Sb}$ phase has been evidenced to a very small extent during the electrochemical reaction, it was found that the small amount of this phase transforms into the room temperature hexagonal P63/ $m m c$ polymorph at full discharge. ${ }^{11}$ This reaction is very different from that of $\mathrm{Sb}$ with $\mathrm{Li}$ during which hexagonal $\mathrm{Li}_{2} \mathrm{Sb}$ forms, followed by the formation of the high-pressure cubic $F m \overline{3} m \mathrm{Li}_{3} \mathrm{Sb}$ phase. ${ }^{24}$ The analysis of these differences in reaction scheme suggests that the reaction of $\mathrm{Cu}_{2} \mathrm{Sb}$ with $\mathrm{Na}$ is not likely to proceed using the same pathway as with $\mathrm{Li}$. The reaction of $\mathrm{Cu}_{2} \mathrm{Sb}$ with $\mathrm{Li}$ discussed earlier is essentially governed by the transformations of a compact fcc $\mathrm{Sb}$ array, which may explain why the reaction with $\mathrm{Na}$ proceeds by the formation of an amorphous phase. In summary, our results support that the reaction can be written as $\mathrm{Cu}_{2} \mathrm{Sb}+3 \mathrm{Na} \leftrightarrow$ $\mathrm{Na}_{3} \mathrm{Sb}+2 \mathrm{Cu}$ via the formation of an intermediate amorphous $\mathrm{Na}-\mathrm{Cu}-\mathrm{Sb}$ phase of varying $\mathrm{Na}$ content possibly coexisting with extruded $\mathrm{Cu}$. The local atomic structure of the electrode material is discussed next.

3.3. Local Atomic Environment of the (Dis)charged Electrode Materials. The discussion of the local environment of $\mathrm{Sb}$ atoms in $\mathrm{Cu}_{2} \mathrm{Sb}, \mathrm{Sb}$, and $\mathrm{Na}_{3} \mathrm{Sb}$ phases is important, as it will serve as a basis for the forthcoming discussion of the local atomic structure of the electrodes measured by XAS and Mössbauer spectroscopy. Figure 4 presents the first and second neighbors of $\mathrm{Sb}$ atoms for (a) $\mathrm{Sb}(R \overline{3} \mathrm{~m})$, (b) $\mathrm{Cu}_{2} \mathrm{Sb}(P 4 / n m m)$, and $(c) \mathrm{Na}_{3} \mathrm{Sb}(P 63 / \mathrm{mmc})$ with additional projections given in Figure S4. The corresponding interatomic distances are listed in Table S1. The first coordination shell in pure $\mathrm{Sb}$ is composed of a distorted octahedron with $3 \mathrm{Sb}$ atoms $\sim 2.90 \AA$ and $3 \mathrm{Sb}$ atoms $\sim 3.36 \AA$. The second coordination shell is composed of $12 \mathrm{Sb}$ atoms with 6 atoms $\sim 4.31 \AA$ and the other 6 atoms $\sim 4.51 \AA$. In the case of $\mathrm{Cu}_{2} \mathrm{Sb}$, the $\mathrm{Sb}$ atoms are 9-fold coordinated by $\mathrm{Cu}$ atoms positioned from 2.63 to $2.84 \AA$. The second coordination shell is composed of $1 \mathrm{Cu}$ atom $\sim 3.48 \AA$, $4 \mathrm{Sb}$ atoms $\sim 3.74 \AA$, and $4 \mathrm{Sb}$ atoms $\sim 4.00 \AA$. Hence, the $\mathrm{Sb}$ atoms are fairly isolated from each other in the structure, as also evident from the distorted fcc representation discussed earlier (Figure 1a). In $\mathrm{Na}_{3} \mathrm{Sb}, \mathrm{Sb}$ is 11 -fold coordinated by $\mathrm{Na}$ atoms located from 3.10 to $3.48 \AA$ with 5 atoms from 3.10 to $3.17 \AA$ and the other 6 atoms at $3.48 \AA$. The second coordination shell is relatively further away with $6 \mathrm{Sb}$ atoms $\sim 5.37 \AA$ and $6 \mathrm{Na}$ and $6 \mathrm{Sb}$ atoms at $\sim 5.68 \AA$. In this structure, $\mathrm{Sb}$ atoms are significantly isolated.

The atomic environment of $\mathrm{Cu}$ was probed using XAS at the $\mathrm{Cu}$ K-edge and $\mathrm{Sb}$ K-edge. XANES at the $\mathrm{Cu}$ K-edge of $\mathrm{Cu}_{2} \mathrm{Sb}$ thin film electrodes (Figure 5a), along with the $\mathrm{Cu}_{2} \mathrm{Sb}$ powder and $\mathrm{Cu}$ foil standards, are discussed next. The inset shows a magnified region around the step edge. Qualitatively, it appears (a)

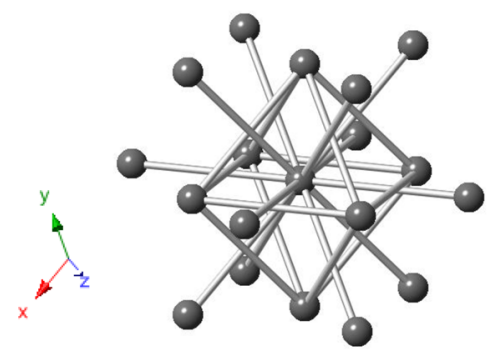

(b)

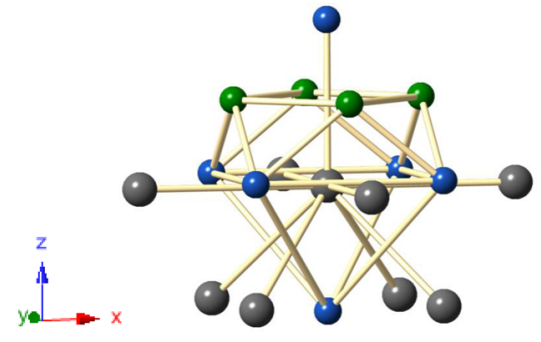

(c)

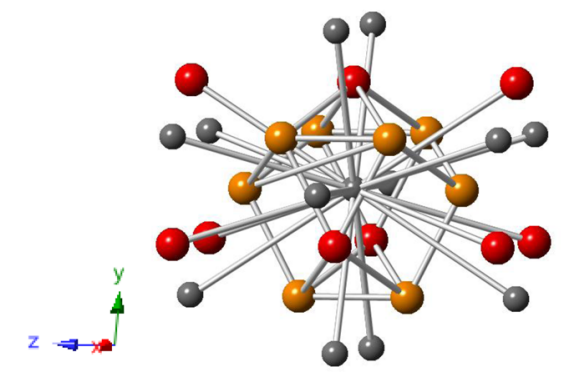

Figure 4. Schematic representations of the atomic surrounding of $\mathrm{Sb}$ in (a) $R \overline{3} m \mathrm{Sb}$, (b) $P 4 / n m m \quad \mathrm{Cu}_{2} \mathrm{Sb}$, and (c) $P 63 / m m c \quad \mathrm{Na}_{3} \mathrm{Sb}$ structures. The $\mathrm{Sb}$-centered first neighbors' polyhedra are depicted with second neighbors. Atoms are represented by green $(\mathrm{Cu} 1)$, blue $(\mathrm{Cu} 2)$, gray $(\mathrm{Sb})$, red (Na1), and orange (Na2) spheres. See Figure S1 for a different view.

that the spectra of the pristine film and electrode charged at $1 \mathrm{~V}$ are nearly identical to the $\mathrm{Cu}_{2} \mathrm{Sb}$ powder. Comparing the spectra in greater detail over the entire range indicates that the pristine film is essentially identical to the powder while the film charged at $1 \mathrm{~V}$ shows quantitative deviations at 8990, 9000, and $9022 \mathrm{eV}$ as well as a small shift in the edge position toward lower photon energy. The changes above the edge are likely changes in the EXAFS oscillations resulting from small structural changes. The shift of the edge toward lower photon energy indicates a small reduction in oxidation state of the $\mathrm{Cu}$ compared to pure $\mathrm{Cu}_{2} \mathrm{Sb}$. For the electrode discharged at $0 \mathrm{~V}$, a feature at low photon energy similar to the $\mathrm{Cu}$ foil is measured. At higher energies, the spectrum lies in between that of $\mathrm{Cu}_{2} \mathrm{Sb}$ and $\mathrm{Cu}$, suggesting that the electrode material might contain regions of $\mathrm{Na}_{x} \mathrm{Cu}_{2-y} \mathrm{Sb}$ and metallic $\mathrm{Cu}$.

The Fourier transform of the $k^{3}$-weighted EXAFS at the $\mathrm{Cu}$ K-edge for the same samples is shown in Figure $5 \mathrm{~b}$. As in XANES, EXAFS of the pristine film is virtually identical to the $\mathrm{Cu}_{2} \mathrm{Sb}$ powder. The results of the fit confirm that the pristine film has essentially the same structural parameters as the $\mathrm{Cu}_{2} \mathrm{Sb}$ powder over the first three nearest neighbors (Table S2). The electrode discharged at $0 \mathrm{~V}$ closely resembles the $\mathrm{Cu}$ foil although the number of $\mathrm{Cu}$ nearest neighbors is significantly smaller in this film $(6.7 \pm 0.5)$ compared to bulk $\mathrm{Cu}(12)$. The smaller coordination number indicates that the average $\mathrm{Cu}$ particle/domain size is very small (few nanometers), which could be expected from a displacement/extrusion reaction of 

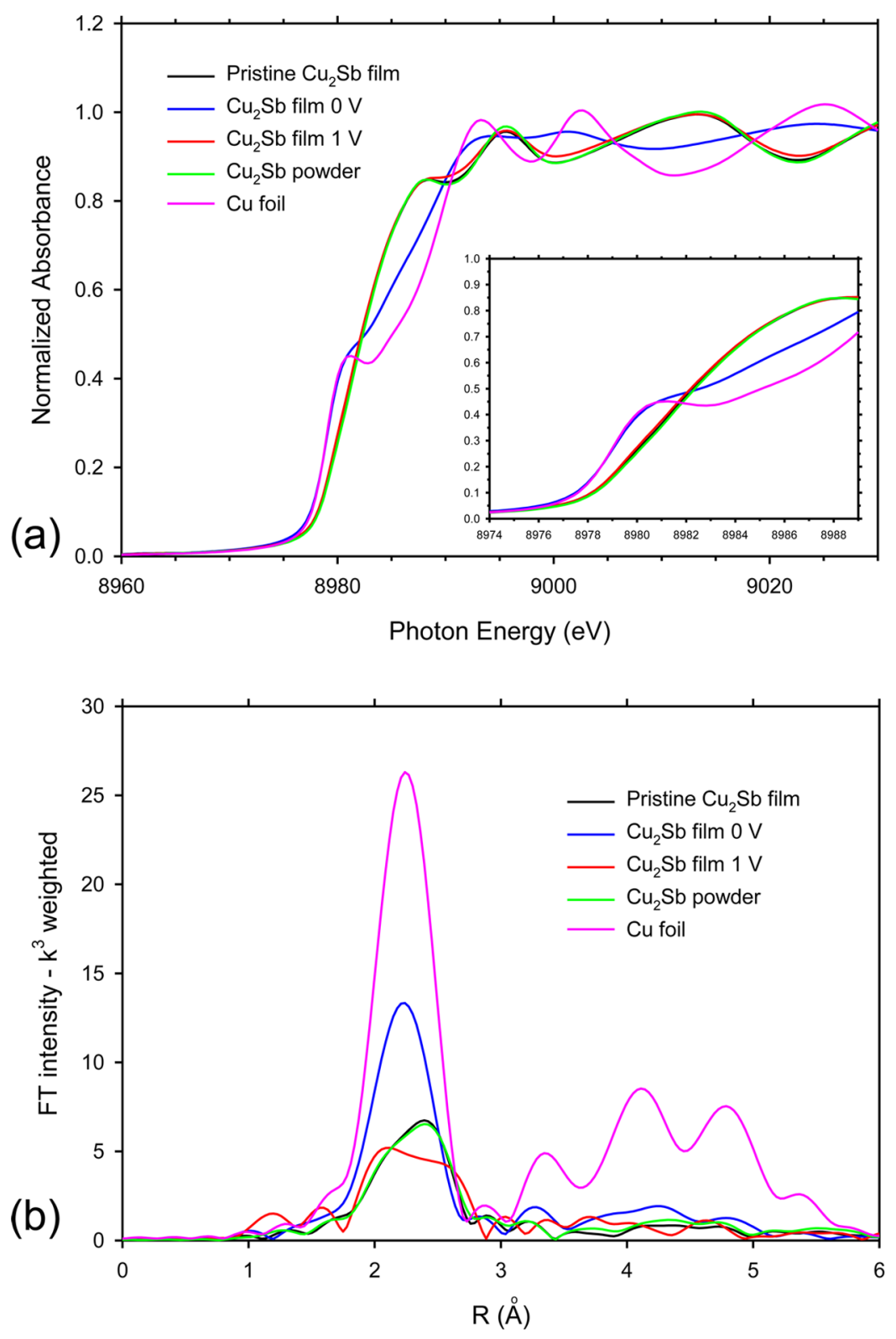

Figure 5. $\mathrm{Cu}$ K-edge (a) XANES and (b) EXAFS data for the pristine $\mathrm{Cu}_{2} \mathrm{Sb}$ thin film and powder, electrode thin films discharged at $0 \mathrm{~V}$ and charged at $1 \mathrm{~V}$, and for $\mathrm{Cu}$ foil. The radial distance reported in (b) is not corrected for the phase shift.

$\mathrm{Cu}$ by $\mathrm{Na}$ at the atomic level. Inclusion of scattering paths contained in $\mathrm{Cu}_{2} \mathrm{Sb}$ did not improve the fit and/or were physically unrealistic (e.g., negative amplitudes or unrealistic nearest-neighbor distances). The EXAFS data collected for the electrode charged at $1 \mathrm{~V}$ look significantly different from either $\mathrm{Cu}_{2} \mathrm{Sb}$ or metallic $\mathrm{Cu}$. The Fourier transform of the EXAFS data is skewed toward low $R$ compared to larger $R$ in the $\mathrm{Cu}_{2} \mathrm{Sb}$ powder. The results of the fit indicate generally smaller coordination numbers, but the ratio is essentially the same as in the $\mathrm{Cu}_{2} \mathrm{Sb}$ powder. Note that the $R$-factor is significantly worse than in any of the other samples analyzed, which suggests that the structure might not be adequately captured by modeling using environments of either $\mathrm{Cu}_{2} \mathrm{Sb}$ or metallic $\mathrm{Cu}$ and highlight the role of the remaining $\mathrm{Na}$ at $1 \mathrm{~V}$ creating a disordered structure.

The $\mathrm{Sb}$ K-edge for the $\mathrm{Cu}_{2} \mathrm{Sb}$ thin film electrodes along with the $\mathrm{Cu}_{2} \mathrm{Sb}, \mathrm{Sb}$, and $\mathrm{Na}_{3} \mathrm{Sb}$ powder standards are discussed next (Figure 6 and Figure S5). The XANES (Figure S5) provides little information as the changes in valence electronic density on the K-shell electron density can be expected to be very small. For this reason, the $\mathrm{Sb}$ environment was also studied with ${ }^{121} \mathrm{Sb}$ Mössbauer spectroscopy (Figure 7), which is sensitive to electron density variation in the tens of $\mathrm{neV}^{25}$ The FT of the EXAFS data for the pristine $\mathrm{Cu}_{2} \mathrm{Sb}$ film and powder are fairly close to that measured for the electrode discharged at $2 \mathrm{~V}$ (Figure 6). At $0 \mathrm{~V}$ there is an important change, compared to the other materials, where the structure has little backscattering at small interatomic distances. The weak backscattering is likely due to the absence of $\mathrm{Sb}$ backscatterers at distances below $5 \AA$ (Table S3), as also found for the $\mathrm{Na}_{3} \mathrm{Sb}$ reference powder. The low atomic number of $\mathrm{Na}$ compared to the energy of more than $30 \mathrm{keV}$ may explain why it does not significantly contribute to the signal at low interatomic distances. The $\mathrm{Cu} \mathrm{K}$-edge XAS results support the formation of pure $\mathrm{Cu}$, and overall the XAS results at both $\mathrm{K}$ edges converge to explain the formation of $\mathrm{Na}_{3} \mathrm{Sb}$ domains. 


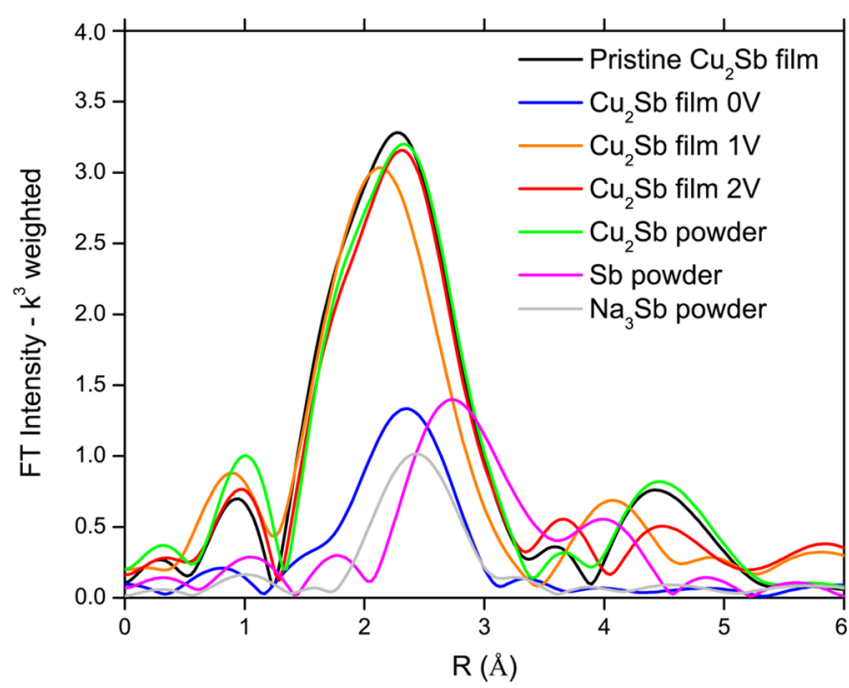

Figure 6. $\mathrm{Sb}$ K-edge EXAFS data for the pristine $\mathrm{Cu}_{2} \mathrm{Sb}$ thin film and powder, electrode thin films discharged at $0 \mathrm{~V}$ and charged at $2 \mathrm{~V}$, and for $\mathrm{Sb}$ and $\mathrm{Na}_{3} \mathrm{Sb}$ powders. The radial distance is not corrected for the phase shift.

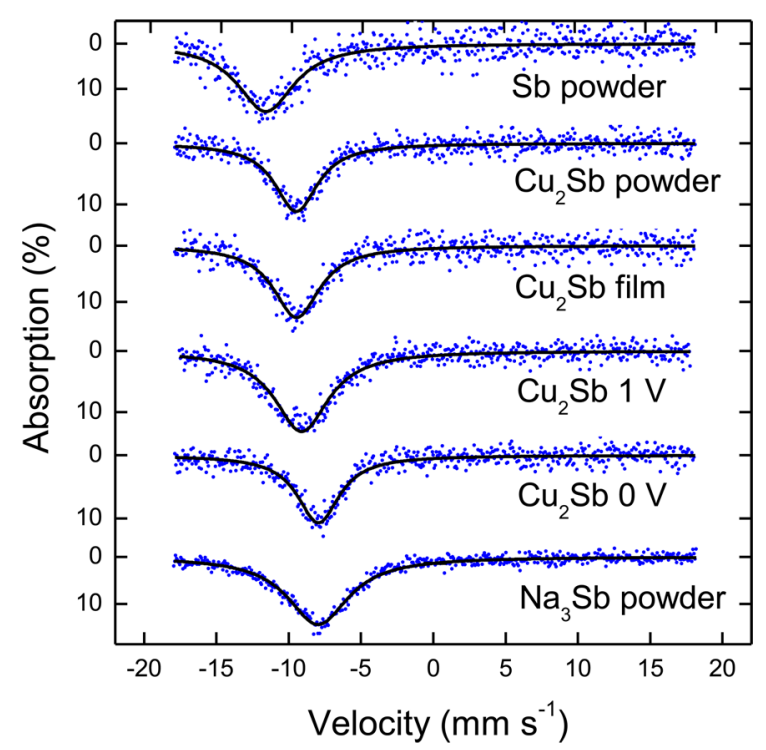

Figure 7. ${ }^{121} \mathrm{Sb}$ Mössbauer spectroscopy data for $\mathrm{Sb}$ powder, $\mathrm{Cu}_{2} \mathrm{Sb}$ powder, $\mathrm{Cu}_{2} \mathrm{Sb}$ thin film, electrode thin film charged at $1 \mathrm{~V}$ and discharged at $0 \mathrm{~V}$, and $\mathrm{Na}_{3} \mathrm{Sb}$ reference powder.

The local atomic ordering for the electrode at $1 \mathrm{~V}$ is significantly different than that at $2 \mathrm{~V}$, as also found with $\mathrm{Cu}$ K-edge data. This is evident from the significantly larger $R$ and Debye-Waller factors and interatomic distances compared to the pristine or charged electrode (Table S3). These results further highlight that the presence of remaining $\mathrm{Na}$ in the structure has a profound impact on the local ordering, which leads to the presence of a disordered structure measured as an amorphous phase by XRD (Figure $3 b$ ).

The chemical environment of $\mathrm{Sb}$ atoms has been further investigated using ${ }^{121} \mathrm{Sb}$ Mössbauer spectroscopy, which is the recoil-free resonant absorption of $\gamma$-rays. This technique measures the relative changes in electronic density at the nucleus as a result of variations in valence electron densities and thereby allows the identification of the chemical environment of the probed atom. ${ }^{25}$ This technique has proved to be very powerful at elucidating the reaction mechanism of various $\mathrm{Sb}$ based anodes for Li-ion batteries. ${ }^{26}$ The spectra for the cycled electrodes as well as for a variety of reference materials including phase pure $\mathrm{Na}_{3} \mathrm{Sb}$ (Figure $\mathrm{S6}$ ) are presented in Figure 7 with corresponding isomer shift values provided in Table 1.

Table 1. ${ }^{121} \mathrm{Sb}$ Mössbauer Isomer Shift $(\delta)$ Measured for the Various $\mathrm{Cu}_{2} \mathrm{Sb}$ Electrodes and Reference Materials

\begin{tabular}{lclc}
\multicolumn{1}{c}{ sample } & $\delta\left(\mathrm{mm} \mathrm{s}^{-1}\right)$ & \multicolumn{1}{c}{ sample } & $\delta\left(\mathrm{mm} \mathrm{s}^{-1}\right)$ \\
$\mathrm{Sb}$ powder & $-11.85 \pm 0.06$ & $\mathrm{Cu}_{2} \mathrm{Sb} 1 \mathrm{~V}$ & $-9.29 \pm 0.04$ \\
$\mathrm{Cu}_{2} \mathrm{Sb}$ powder & $-9.67 \pm 0.04$ & $\mathrm{Cu}_{2} \mathrm{Sb} \mathrm{0} \mathrm{V}$ & $-8.10 \pm 0.04$ \\
$\mathrm{Cu}_{2} \mathrm{Sb} \mathrm{film}$ & $-9.65 \pm 0.05$ & $\mathrm{Na}_{3} \mathrm{Sb}$ powder & $-7.95 \pm 0.03$ \\
\hline
\end{tabular}

The isomer shift of the starting $\mathrm{Cu}_{2} \mathrm{Sb}$ powder $\left(-9.67 \mathrm{~mm} \mathrm{~s}^{-1}\right)$ is in fairly good agreement with the value of $-9.2 \mathrm{~mm} \mathrm{~s}^{-1}$ predicted by Sharma et al. using density functional theory calculations. ${ }^{27}$ They also reported a predicted value of $-8.2 \mathrm{~mm}$ $\mathrm{s}^{-1}$ for $\mathrm{InSb}$, which is rather close to the experimental value of $-8.6 \mathrm{~mm} \mathrm{~s}^{-1}$, 28 and in both cases the predictions slightly overestimate the experimental isomer shift values by about 0.4 $\mathrm{mm} \mathrm{s}^{-1}$. The isomer shift of $\mathrm{Cu}_{2} \mathrm{Sb}$ is much more positive than that of our $\mathrm{Sb}$ powder $\left(-11.85 \mathrm{~mm} \mathrm{~s}^{-1}\right)$ or of $\mathrm{SnSb}(-10.5 \mathrm{~mm}$ $\left.\mathrm{s}^{-1}\right)^{28}$ but is more negative than the values reported for other $\mathrm{Sb}$ intermetallics such as $\mathrm{AlSb}, \mathrm{GaSb}$, InSb, and $\mathrm{CdSb}$ characterized by isomer shifts from -7.8 to $-8.6 \mathrm{~mm} \mathrm{~s}^{-1}$. $^{28}$ For ${ }^{121} \mathrm{Sb}$ Mössbauer spectroscopy, the increasing (decreasing) isomer shift reflects a decrease (increase) in the $\mathrm{Sb}$ electron density at the nucleus. The electron density is dependent on the numbers of $5 \mathrm{~s}$ and $5 \mathrm{p}$ electrons and generally increases with the increase of $5 \mathrm{~s}$ electrons and with the decrease of $5 \mathrm{p}$ electrons. ${ }^{28}$ For $\mathrm{Cu}_{2} \mathrm{Sb}$, it is clear that the isomer shift is less positive than those for the $\mathrm{M}-\mathrm{Sb}$ intermetallics of $\mathrm{In}, \mathrm{Cd}, \mathrm{Ga}$, and $\mathrm{Al}$, especially $\mathrm{Al}$, which can be related to the larger electronegativity of $\mathrm{Cu}$ (1.90), using Pauling's scale for example, compared to In (1.78), Ga (1.81), Cd (1.69), and $\mathrm{Al}$ (1.61). Conversely, the more positive isomer shift of $\mathrm{Cu}_{2} \mathrm{Sb}$ compared to $\mathrm{SnSb}$ or $\mathrm{Sb}$ can be associated with the larger electronegativity of $\mathrm{Sn}(1.96)$ and $\mathrm{Sb}$ (2.05) compared to $\mathrm{Cu}$. $\mathrm{As} \mathrm{Sb}$ is the most electronegative element in this series, alloying with an atom of lower electronegativity will result in a higher number of effective valence electrons overall. As such, the electronic configuration of $\mathrm{Sb}(5 \mathrm{~s}=1.91 / 5 \mathrm{p}=3.09$, formally $5 \mathrm{~s}$ $=2 / 5 p=3)$, effectively changes with an increase of the $5 p$ electrons but a decrease of the 5 s electrons ${ }^{28}$ and leads to the variety of isomer shifts discussed above.

The thin film material created by sputtering the powder target is characterized by a spectrum with an isomer shift $\left(-9.65 \mathrm{~mm} \mathrm{~s}^{-1}\right)$ quasi-identical to that of the powder, which confirms that the local atomic ordering of the film is similar to that of the powder. This result further supports the findings from the other characterizations. After a discharge to $0 \mathrm{~V}$ and a charge at $1 \mathrm{~V}$, a spectrum characterized by an isomer shift of $-9.29 \mathrm{~mm} \mathrm{~s}^{-1}$ is measured, which is fairly close to that of the pristine material $\left(-9.65 \mathrm{~mm} \mathrm{~s}^{-1}\right)$. The difference of about 0.35 $\mathrm{mm} \mathrm{s}^{-1}$ can be related to the absence of full desodiation due to the use of the charge cutoff of $1 \mathrm{~V}$. This result is in good agreement with the XAS and XRD results that indicated a significant structural disordering of the electrode material at $1 \mathrm{~V}$ concomitant with the presence of an amorphous phase. At full sodiation $(0 \mathrm{~V})$, the spectrum is composed of a singlet with an isomer shift of $-8.10 \mathrm{~mm} \mathrm{~s}^{-1}$, which is very close to what is measured for the $\mathrm{Na}_{3} \mathrm{Sb}$ reference powder $\left(-7.95 \mathrm{~mm} \mathrm{~s}^{-1}\right)$. 
The isomer shift value obtained for the $\mathrm{Na}_{3} \mathrm{Sb}$ powder is in good agreement with the reported value of $-0.67 \mathrm{~mm} \mathrm{~s}^{-1}$ with respect to the isomer shift of $\mathrm{InSb}^{29}$ which is equal to -7.93 $\mathrm{mm} \mathrm{s}^{-1}$ assuming $-8.6 \mathrm{~mm} \mathrm{~s}^{-1}$ for the isomer shift of InSb with respect to a $\mathrm{BaSnO}_{3}$ source. ${ }^{28}$ The slightly more negative isomer shift measured for the discharged electrodes $(-8.10 \mathrm{~mm}$ $\left.\mathrm{s}^{-1}\right)$ compared to $\mathrm{Na}_{3} \mathrm{Sb}\left(-7.95 \mathrm{~mm} \mathrm{~s}^{-1}\right)$ can be related to the absence of full sodiation of the very thick films employed for the Mössbauer measurements; nonetheless, the result suggests that the final discharge product is $\mathrm{Na}_{3} \mathrm{Sb}$, as evidenced by XRD and XAS results.

\section{CONCLUSIONS}

The electrochemical performance of $\mathrm{Cu}_{2} \mathrm{Sb}$ thin film electrodes during the reaction with $\mathrm{Na}$ has been revisited using FEC as an electrolyte additive. The addition of FEC is found to drastically improve the electrode capacity retention with about $250 \mathrm{mAh}$ $\mathrm{g}^{-1}$ retained for 200 cycles. On the other hand, the use of FEC increases the overpotentials during the first discharges, as systematically found on several other (inter)metallic anode systems. The reaction mechanism of $\mathrm{Cu}_{2} \mathrm{Sb}$ anode has been unraveled using XRD and $\mathrm{Cu} \mathrm{K}$-edge and $\mathrm{Sb} \mathrm{K}$-edge XAS. In addition, the present paper discloses for the first time the Mössbauer isomer shift of $\mathrm{Cu}_{2} \mathrm{Sb}\left(-9.67 \mathrm{~mm} \mathrm{~s}^{-1}\right.$ vs $\left.\mathrm{BaSnO}_{3}\right)$ as well as the changes in hyperfine parameters for the (dis)charged electrodes. The XRD results indicate that $\mathrm{Cu}_{2} \mathrm{Sb}$ can undergo a fully reversible transformation into $\mathrm{Na}_{3} \mathrm{Sb}$ via an amorphous phase. The formation of $\mathrm{Na}_{3} \mathrm{Sb}$ domains at full discharge $(0 \mathrm{~V})$ is further confirmed by XAS and Mössbauer spectroscopy results with the aid of a $\mathrm{Na}_{3} \mathrm{Sb}$ reference compound. The formation of $\mathrm{Cu}_{2} \mathrm{Sb}$, indicating full structural reversibility, is evidenced by XRD and XAS results when the charge is conducted up to 1.5 or $2 \mathrm{~V}$ with lower cutoff currents. Finally, the results demonstrate that restricting the charge voltage to $1 \mathrm{~V}$ results in the formation of a disordered structure (amorphous phase).

\section{ASSOCIATED CONTENT}

\section{S Supporting Information}

Crystal structure representations, XRD, XAS, and tables with fits to the data. This material is available free of charge via the Internet at http://pubs.acs.org.

\section{AUTHOR INFORMATION}

\section{Corresponding Authors}

*E-mail loic_baggetto@yahoo.fr (L.B.).

*E-mail veithgm@ornl.gov (G.M.V.).

\section{Notes}

The authors declare no competing financial interest.

\section{ACKNOWLEDGMENTS}

A portion of this work (L.B., G.M.V. (synthesis, electrochemistry, XRD), R.R.U. (TEM)) was supported by the U.S. Department of Energy, Office of Basic Energy Sciences, Division of Materials Sciences and Engineering, under contract with UT-Battelle, LLC. H.Y.H., C.E.J., and J.A.J. (Mossbauer) acknowledge support from the Center for Laser Applications and the University of Tennessee Space Institute. K.J.C. and Y.S.M. (XAS) acknowledge support from the National Science Foundation under Award DMR105717. D.R.M. (XAS) was financially supported by the Division of Chemical Sciences, Geosciences, and Biosciences, Office of Basic Energy Sciences,
U.S. Department of Energy, under Contract DE-AC0500OR22725 with Oak Ridge National Laboratory, managed and operated by UT-Battelle, LLC. XAS experiments were conducted at the National Synchrotron Light Source, Brookhaven National Laboratory, supported by the US Department of Energy, Office of Science, Office of Basic Energy Sciences, under Contract DE-AC02-98CH10886 with additional support through the Synchrotron Catalysis Consortium under Grant DE-FG02-05ER15688.

\section{REFERENCES}

(1) Palomares, V.; Serras, P.; Villaluenga, I.; Hueso, K. B.; CarreteroGonzález, J.; Rojo, T. Na-Ion Batteries, Recent Advances and Present Challenges to Become Low Cost Energy Storage Systems. Energy Environ. Sci. 2012, 5, 5884-5901.

(2) Ellis, B. L.; Nazar, L. F. Sodium and Sodium-Ion Energy Storage Batteries. Curr. Opin. Solid State Mater. Sci. 2012, 16, 168-177.

(3) Kim, S.-W.; Seo, D.-H.; Ma, M.; Ma, G.; Kang, K. Electrode Materials for Rechargeable Sodium-Ion Batteries: Potential Alternatives to Current Lithium-Ion Batteries. Adv. Energy Mater. 2012, 2, $710-721$.

(4) Yabuuchi, N.; Kajiyama, M.; Iwatate, J.; Nishikawa, H.; Hitomi, S.; Okuyama, R.; Yasuhiro, R.; Komaba, S. P2-type $\mathrm{Na}_{\mathrm{x}}\left[\mathrm{Fe}_{1 / 2} \mathrm{Mn}_{1 / 2}\right] \mathrm{O}_{2}$ Made from Earth-Abundant Elements for Rechargeable Na Batteries. Nat. Mater. 2012, 11, 512-517.

(5) Senguttuvan, P.; Rousse, G.; Seznec, V.; Tarascon, J.-M.; Palacín, M. R. $\mathrm{Na}_{2} \mathrm{Ti}_{3} \mathrm{O}_{7}$ : Lowest Voltage Ever Reported Oxide Insertion Electrode for Sodium Ion Batteries. Chem. Mater. 2011, 23, 41094111.

(6) Ponrouch, A.; Marchante, E.; Courty, M.; Tarascon, J.-M.; Palacín, M. R. In Search of An Optimized Electrolyte for Na-Ion Batteries. Energy Environ. Sci. 2012, 5, 8572-8583.

(7) Komaba, S.; Murata, W.; Ishikawa, T.; Yabuuchi, N.; Ozeki, T.; Nakayama, T.; Ogata, A.; Gotoh, K.; Fujimara, K. Electrochemical Na Insertion and Solid Electrolyte Interphase for Hard-Carbon Electrodes and Application to Na-Ion Batteries. Adv. Funct. Mater. 2011, 21, 3859-3867.

(8) Baggetto, L.; Meisner, R. P.; Ganesh, P.; Unocic, R. R.; Jumas, J.C.; Bridges, C. A.; Veith, G. M. Characterization of Sodium Ion Electrochemical Reaction with Tin Anodes: Experiment and Theory. J. Power Sources 2013, 234, 48-59.

(9) Ellis, L. D.; Hatchard, T. D.; Obrovac, M. N. Reversible Insertion of Sodium in Tin. J. Electrochem. Soc. 2012, 159, A1801-A1805.

(10) Baggetto, L.; Ganesh, P.; Sun, C.-N.; Meisner, R. A.; Zawodzinski, T. A.; Veith, G. M. Intrinsic Thermodynamic and Kinetic Properties of Sb Electrodes for Li-Ion and Na-Ion Batteries: Experiment and Theory. J. Mater. Chem. A 2013, 1, 7985-7994.

(11) Darwiche, A.; Marino, C.; Sougrati, M. T.; Fraisse, B.; Stievano, L.; Monconduit, L. Better Cycling Performances of Bulk Sb in Na-Ion Batteries Compared to Li-Ion Systems: An Unexpected Electrochemical Mechanism. J. Am. Chem. Soc. 2012, 134, 20805-20811.

(12) Park, C.-M.; Kim, J.-H.; Kim, H.; Sohn, H.-J. Li-Alloy Based Anode Materials for Li Secondary Batteries. Chem. Soc. Rev. 2010, 39, 3115-3141.

(13) Darwiche, A.; Sougrati, M. T.; Fraisse, B.; Stievano, L.; Monconduit, L. Facile Synthesis and Long Cycle Life of $\mathrm{SnSb}$ as Negative Electrode Material for Na-Ion Batteries. Electrochem. Commun. 2013, 32, 18-21.

(14) Baggetto, L.; Jumas, J.-C.; Górka, J.; Bridges, C. A.; Veith, G. M. Predictions of Particle Size and Lattice Diffusion Pathway Requirements for Sodium-Ion Anodes Using $\eta$ - $\mathrm{Cu}_{6} \mathrm{Sn}_{5}$ Thin Films as a Model System. Phys. Chem. Chem. Phys. 2013, 15, 10885-10894.

(15) Baggetto, L.; Allcorn, E.; Manthiram, A.; Veith, G. M. $\mathrm{Cu}_{2} \mathrm{Sb}$ Thin Films as Anode for Na-Ion Batteries. Electrochem. Commun. 2013, 27, 168-171.

(16) Nam, D.-H.; Hong, K.-S.; Lim, S.-J.; Kwon, H.-S. Electrochemical Synthesis of a Three-Dimensional Porous $\mathrm{Sb} / \mathrm{Cu}_{2} \mathrm{Sb}$ Anode for Na-Ion Batteries. J. Power Sources 2014, 247, 423-427. 
(17) Baggetto, L.; Marszewski, M.; Górka, J.; Jaroniec, M.; Veith, G. M. AlSb Thin Films as Negative Electrodes for Li-Ion and Na-Ion Batteries. J. Power Sources 2013, 243, 699-705.

(18) Baggetto, L.; Allcorn, E.; Unocic, R. R.; Manthiram, A.; Veith, G. M. $\mathrm{Mo}_{3} \mathrm{Sb}_{7}$ as a Very Fast Anode Material for Lithium-Ion and Sodium-Ion Batteries. J. Mater. Chem. A 2013, 1, 11163-11169.

(19) Baggetto, L.; Keum, J. L.; Browning, J. F.; Veith, G. M. Germanium as Negative Electrode Material for Sodium-Ion Batteries. Electrochem. Commun. 2013, 34, 41-44.

(20) Webb, S. A.; Baggetto, L.; Bridges, C. A.; Veith, G. M. The Electrochemical Ractions of Pure Indium with $\mathrm{Li}$ and $\mathrm{Na}$ : Anomalous Electrolyte Decomposition, Benefits of FEC Additive, Phase Transitions and Electrode Performance. J. Power Sources 2014, 248, $1105-1117$

(21) Ravel, B.; Newville, M. ATHENA, ARTEMIS, HEPHAESTUS: Data Analysis for X-ray Absorption Spectroscopy Using IFEFFIT. J. Synchrotron Radiat. 2005, 12, 537-541.

(22) Fransson, L. M. L.; Vaughey, J. T.; Benedek, R.; Edström, K.; Thomas, J. O.; Thackeray, M. M. Phase Transitions in Lithiated $\mathrm{Cu}_{2} \mathrm{Sb}$ Anodes for Lithium Batteries: an In Situ X-ray Diffraction Study. Electrochem. Commun. 2001, 3, 317-323.

(23) Morcrette, M.; Larcher, D.; Tarascon, J.-M.; Edström, K.; Vaughey, J. T.; Thackeray, M. M. Influence of Electrode Microstructure on the Reactivity of $\mathrm{Cu}_{2} \mathrm{Sb}$ with Lithium. Electrochim. Acta 2007, 52, 5339-5345.

(24) Hewitt, K. C.; Beaulieu, L. Y.; Dahn, J. R. Electrochemistry of $\mathrm{InSb}$ as a Li Insertion Host: Problems and Prospects. J. Electrochem. Soc. 2001, 148, A402-A410.

(25) Dunlap, B. D.; Kalvius, G. M. In Mössbauer Isomer Shifts; Shenoy, G. K., Wagner, F. E., Eds.; North-Holland Publishing Company: Amsterdam, 1978; pp 18-23.

(26) Aldon, L.; Garcia, A.; Olivier-Fourcade, J.; Jumas, J.-C.; Fernández-Madrigal, F. J.; Lavela, P.; Pérez Vicente, C.; Tirado, J.-L. Lithium Insertion Mechanism in Sb-Based Electrode Materials from ${ }^{121}$ Sb Mössbauer Spectrometry. J. Power Sources 2003, 119-121, 585590.

(27) Sharma, S.; Dewhurst, J. K.; Ambrosch-Draxl, C. Lithiation of InSb and $\mathrm{Cu}_{2} \mathrm{Sb}$ : A Theoretical Investigation. Phys. Rev. B 2004, 70, 104110.

(28) Lippens, P. E. Mössbauer Isomer Shifts of Crystalline Antimony Compounds. Solid State Commun. 2000, 113, 399-403.

(29) Kitadai, K.; Takahashi, M.; Takeda, M. ${ }^{121}$ Sb Mössbauer Spectra of Alkali Metal Antimonides $\mathrm{M}_{3} \mathrm{Sb}\left(\mathrm{M}_{3}=\mathrm{Na}_{3}, \mathrm{~K}_{3}, \mathrm{Na}_{2} \mathrm{~K}, \mathrm{Rb}_{3}\right)$. J. Radioanal. Nucl. Chem. 2003, 255, 311-314. 